\title{
Valoraciones del alumnado de Educación Primaria sobre lecturas digitales diseñadas con UDL Book-Builder como apoyo en los procesos lectores
}

\author{
José Manuel Sánchez-Serrano ${ }^{*}$ ), Carmen Alba-Pastor $\left(^{*}\right)$ y Pablo Sánchez-Antolín $\left(^{* *}\right.$ ) \\ ${ }^{(*)}$ Universidad Complutense de Madrid - España $\left(^{* *}\right)$ Universidad de Castilla la Mancha - España
}

\begin{abstract}
RESUMEN
La diversidad en las aulas es un hecho y atenderla un reto a enfrentar para todos los docentes. Distintas investigaciones muestran que ciertas tecnologías tienen potencial para apoyar procesos de aprendizaje implicados en la lectura, aunque son escasos los trabajos que consideran la visión del alumnado en la evaluación de dicho potencial. Este estudio descriptivo tiene como objetivo conocer las valoraciones de los usuarios sobre un conjunto de lecturas digitales diseñadas con UDL Book-Builder, una herramienta on-line para la creación de libros multimedia según los principios del Diseño Universal para el Aprendizaje, y sobre las características que incorpora, como son ayudantes virtuales, lector de texto, audio o glosario multimedia. Se digitalizaron 24 lecturas que fueron utilizadas durante un curso escolar en tres centros de Educación Primaria. Tras ello, una muestra de 117 estudiantes de primer y segundo curso respondieron a una encuesta para valorar los materiales y sus características. El análisis cuantitativo de los datos muestra que el alumnado identifica diferentes formas en las que éstas actúan como «andamiaje» de su aprendizaje y la mayoría prefiere estas lecturas digitales frente a los mismos textos en formato impreso. Los datos sugieren que el uso de estos recursos tecnológicos podría ser adecuado para responder a la diversidad en los procesos lectores y pueden resultar de utilidad a los docentes en la selección de las herramientas digitales más adecuadas para lograrlo.
\end{abstract}

Palabras Clave: Diseño Universal para el Aprendizaje, TIC, Lecturas digitales, Educación Primaria, Evaluación de recursos digitales.

\section{Primary School students' feedback about digital texts designed using UDL Book-Builder, as support in the reading processes}

\section{ABSTRACT}

Diversity in classrooms is an indisputable fact and teachers are challenged to deal with it. Research findings show that technologies own the potential to support different learning processes and that certain technical functionalities have positive effects on the acquisition of literacy skills. However, there are few studies that take into account the students' vision to assess that potential. This descriptive study analyzes the users' feedback about digital readings designed using UDL Book-Builder application, a free online tool for creating interactive books, based on the Universal Design for Learning principles, which allows to incorporate features such as coaches, text reader, audio or multimedia glossary. Twenty-four digital texts were used in reading classes of three primary education centres throughout the school year along with the printed version. After that, a sample of 117 first and second-year students was interviewed to respond to a survey so that they could value these functionalities. Quantitative analysis of the results shows that students identify different ways in which these act as scaffolding of their learning and most of them prefer these digital readings versus the same texts in print. The data suggest that use of these technological resources might be appropriate to respond to diversity in reading processes and could be useful to teachers in selecting appropriate digital tools to achieve it.

Keywords: Universal Design for Learning, ICT, Digital texts, Primary Education, Digital resources evaluation.

\section{Introducción y estado de la cuestión}

La diversidad del alumnado es un rasgo definitorio del Sistema Educativo español, lo que conlleva que en las aulas coexistan formas de aprender también muy diversas y a las que debe darse respuesta desde un enfoque inclusivo. Un caso claro de aprendizaje en el que se evidencia la diversidad del alumnado en los primeros cursos de Educación Primaria (EP) es la competencia lectora. Las primeras aproximaciones a la lectura y la escritura se realizan en entornos informales 
de forma previa a la escolarización (Jiménez y O'Shanahan, 2008), por lo que en función de las distintas interacciones que el alumnado haya mantenido con el lenguaje escrito, se dan diferencias en el nivel de desarrollo de los procesos asociados a dichas destrezas. Investigaciones como las de González y Delgado (2009) demuestran que ya al comienzo de EP los estudiantes en los que se refuerza la competencia lectora obtienen mejores resultados académicos.

La necesidad de atender la diversidad está llevando a buscar nuevos modelos y enfoques de aprendizaje individualizados que respondan a las necesidades de todo el alumnado y contribuyan a la mejora de sus resultados académicos (Méndez, 2015; Hidalgo y Manzano, 2014). En muchos de ellos, las tecnologías educativas se identifican como un elemento fundamental para lograrlo (García-Valcárcel y Tejedor, 2017). Una de las propuestas más prometedoras para orientar la atención a la diversidad la ofrece el Diseño Universal para el Aprendizaje (DUA), que en combinación con las Tecnologías de la Información y la Comunicación (TIC) permite explorar vías que den respuesta a todo el alumnado teniendo en cuenta sus preferencias, posibilidades y limitaciones.

\subsection{Diversidad y desarrollo de los procesos lectores}

Desde un enfoque cognitivo, el desarrollo de la competencia lectora depende de la integración de dos operaciones mentales definidas en términos de procesos (Méndez y Fidalgo, 2009): microprocesos, relacionados con la decodificación y reconocimiento de las palabras escritas, y macroprocesos, relativos a la comprensión del texto. Concretamente, son cuatro los procesos que intervienen (Cuetos, 1990):

- Perceptivos. Reconocimiento de letras.

- Léxicos. Acceso al significado de la palabra a través de dos vías: fonológica o indirecta, mediante un proceso de decodificación; y léxica, visual o directa, reconociendo la palabra instantáneamente, de un vistazo.

- Sintácticos. Relaciones entre palabras y entre partes del texto.

- Semánticos. Compresión del mensaje, integración en la memoria y vinculación con conocimientos previos.

En primer y segundo curso de EP los procesos léxicos cobran una mayor importancia, al encontrarse el alumnado en las etapas de desarrollo de la lectura alfabética (decodificación) y ortográfica (reconocimiento) respectivamente (Frith, 1985).

Determinadas características de los medios digitales ofrecen una excelente oportunidad para apoyar al alumnado en cada uno de estos procesos, actuando como andamiajes en la construcción de su aprendizaje y ajustándose a sus necesidades y preferencias individuales.

\subsection{Contribución de las TIC a la atención a la diversidad desde el modelo DUA}

Si bien existe consenso en que el mero uso de las TIC no garantiza una mejora en los resultados académicos (Morra y Reynolds, 2010; Hattie, 2009), los estudios señalan su potencialidad para apoyar los procesos de enseñanza y aprendizaje de forma más efectiva que los medios tradicionales (Coll, 2009). De la revisión de diferentes trabajos puede concluirse que las TIC aumentan los niveles de motivación y concentración, refuerzan la comprensión de conceptos gracias a su naturaleza visual, permiten una mayor atención a las necesidades individuales, promueven la implicación hacia la asignatura y mejoran las habilidades de expresión oral (Claro, 2010; Estévez, 2012; Sáez, 2012).

EL DUA es un modelo teórico-práctico propuesto en Estados Unidos por el Center for Applied Special Technology (CAST) para facilitar el diseño de currículos educativos flexibles, que se operativiza en un marco estructurado en torno a tres principios y varias pautas (Rose y Meyer, 2002). La consideración de estos principios en el diseño de materiales curriculares digitales permite dotarlos de la flexibilidad necesaria para responder a las características individuales del alumnado, reportando beneficios en los procesos de enseñanza-aprendizaje (Azorín y Arnáiz, 2013; Alba-Pastor, Zubillaga y Sánchez-Serrano, 2015).

Aunque se trata de un enfoque metodológico didáctico, no un modelo tecnológico, el DUA encuentra en las TIC un aliado para lograr sus objetivos (Rose, Gravel y Domings, 2012; Alba-Pastor, 2016), pues "va más allá de la enseñanza diversificada en lo que se refiere a escenarios, [e] incluye y aprovecha el espacio digital" (García y Cotrina, 2012, p. 131). Así, la importancia de las TIC en la aplicación del DUA es indiscutible (Edyburn, 2010), ya que ciertas funcionalidades como la flexibilidad que brindan en los modos de navegación o la versatilidad para presentar contenidos accesibles (Zubillaga y Alba-Pastor, 2013), suponen un claro potencial para atender la diversidad y personalizar el aprendizaje. Un ejemplo de dichas funcionalidades es incorporar subtítulos para posibilitar el acceso a contenidos audiovisuales, aumentando los niveles de comprensión independientemente de la lengua materna (Kruger, Doherty y Soto-Sanfiel, 2017).

La utilización del DUA permite introducir cambios en las prácticas docentes relacionadas con las TIC y en la creación de materiales digitales (Meyer, Rose, y Gordon, 2014; Novak, 2014). Sin embargo, diferentes estudios señalan la baja capacitación de los docentes de EP tanto para usar los medios digitales con el propósito de potenciar el aprendizaje de alumnado con discapacidad (Fernández-Batanero, Román y El-Homrani, 2017), como para diseñar y adaptar materiales didácticos inclusivos (González-Gil, Martín-Pastor y Orgaz-Baz). Se torna necesario orientar al profesorado en la selección y uso de las TIC que apoyen adecuadamente diferentes tipos de aprendizaje.

\subsection{Efectos de las tecnologías educativas en el aprendizaje de la lectura}

En el caso concreto del desarrollo de la competencia lectora en EP, algunas de las funcionalidades que incluyen los textos digitales (modificar tamaño de letra, contraste, color; conversores texto-audio; hiperenlaces; interactividad) son consideradas mejoras (Reynolds, 2011) que los hacen más motivadores y útiles para el aprendizaje de la lectura que los libros de texto impresos.

De hecho, la utilización de recursos digitales en el aprendizaje de la lectura está cada vez más presente en las aulas y desde etapas más tempranas (Moody, 2010) debido a su potencial para aumentar la motivación y mejorar la atención del alumnado con dificultades lectoras. Cuadrado y Fernández (2009) presentan una experiencia de elaboración de materiales digitales que, al considerar elementos en el diseño como la conexión con los conocimientos previos, la interactividad o la flexibilidad para ajustarse a necesidades individuales, inciden en el refuerzo de los procesos reflexivos del alumnado.

Algunos trabajos que exploran los beneficios de los textos digitales en los procesos de adquisición de la lectura (Biancarosa y Griffiths, 2012; Narkon y Wells, 2013; Soria, 2015) consideran que este tipo de recursos hacen más accesibles los contenidos a todos los estudiantes y se adaptan en mayor medida a sus necesidades 
y preferencias individuales. En la misma línea, el trabajo de González (2014) realizado con estudiantes de tercer y cuarto curso de EP evidenció que el tipo de diseño de textos digitales tiene un efecto clave en la comprensión verbal, indicando que incorporar funcionalidades como conversores texto-voz, glosarios y gráficos animados refuerzan el desarrollo de diferentes habilidades lectoras. Asimismo, también señala el potencial de estos recursos para apoyar el aprendizaje de la lectura desde preescolar hasta quinto de Primaria y para ayudar a superar los desfases entre el alumnado con dificultades lectoras. Por su parte, el estudio de Moody (2010) corrobora que los libros digitales tienen un efecto positivo en la motivación para leer, en la adquisición de la competencia lectora y en el lenguaje oral, especialmente cuando su diseño incluye apoyos interactivos (andamiajes) vinculados con el vocabulario y la comprensión.

\subsection{Valoración de materiales digitales por parte del alumnado}

El papel de las TIC en el aprendizaje también se ha estudiado tomando como referencia las valoraciones y percepciones de los destinatarios directos de las mismas: alumnos y profesores. Si bien es posible encontrar trabajos de este tipo en el ámbito universitario (Philip y Moon, 2013), resultan especialmente interesantes, aunque escasos, aquellos que se circunscriben a la enseñanza obligatoria.

Los resultados de un estudio de De Oliveira, Camacho y Gisbert acerca de las percepciones que los estudiantes de sexto curso de EP y su maestro tenían sobre el libro de texto electrónico apuntaban que todos preferían su uso frente al libro de texto impreso, destacando como aspectos positivos "la facilidad para realizar actividades y encontrar información, la posibilidad de ver imágenes y vídeos, y la novedad" (2014, p. 92).

En la misma línea, otra investigación recogió las valoraciones que alumnado con trastorno del espectro autista y sus profesores hacían sobre un conjunto de lecturas diseñadas con la herramienta digital Book-Builder siguiendo los principios del DUA. El alumnado mostró preferencia por el texto digital sobre el impreso y señalaron que el glosario o los ayudantes virtuales eran las funcionalidades que más ayuda prestaban durante el aprendizaje. Los profesores coincidieron en señalar la utilidad de Book-Builder para favorecer la inclusión, personalizar la enseñanza y mejorar los niveles de vocabulario y comprensión (Knight, Wood, Spooner, Browder y O'Brien, 2015).

El presente trabajo sigue esta última línea de investigación, indagando sobre las valoraciones que el alumnado de primer y segundo curso de EP hace de un conjunto de lecturas que fueron digitalizadas utilizando Book-Builder, una "plataforma para elaborar textos electrónicos que se basa en la investigación sobre comprensión lectora y en los principios del DUA" (Dalton, 2014, p. 543) y que incorpora varias características dirigidas a apoyar los distintos procesos cognitivos que intervienen en la lectura (http://bookbuilder.cast.org/). La literatura analizada apunta que determinadas características técnicas de las TIC contribuyen al desarrollo de la competencia lectora. Ahora bien, ¿valoran los alumnos el potencial de las características que incorpora Book-Builder para apoyar los procesos referidos o la percepción de su utilidad se reduce a la mera motivación que despierta su uso? Dado que teóricamente el nivel de desarrollo de los procesos lectores varía con la edad, ¿existen diferencias en la valoración de las características en función del curso? Apenas se encuentran trabajos con este tipo de información, por lo que responder a estas preguntas puede ser de gran valor para orientar tanto el diseño de materiales curriculares digitales como la elección de estos por parte de los docentes para su uso en el aula.

\section{Método}

En el marco de un proyecto I+D+i desarrollado entre 2012 y 2015, el presente estudio exploró la percepción de una muestra de estudiantes de primer y segundo curso de Educación Primaria acerca de cómo determinadas características tecnológicas incorporadas a una serie de lecturas digitalizadas con Book-Builder pueden contribuir a apoyar el aprendizaje de la lectura, así como la preferencia de uso de estas sobre sus homólogas en formato de texto impreso.

Se diseñó un estudio descriptivo que, a partir de la experiencia de uso del alumnado con las lecturas digitalizadas, permitió recabar datos verbales del alumnado a través de un cuestionario susceptibles de ser codificados y tratados cuantitativamente. Si bien este trabajo comparte la línea de investigación de enfoques clásicos como la "investigación sobre medios" (Salomon y Clark, 1977) y los estudios centrados en las características de diseño de los medios (Ely, 1987), dado el objetivo y metodología usada, se inscribe entre aquellas investigaciones que persiguen evaluar la tecnología educativa partiendo de la experiencia del alumnado como usuarios de esta (Druin, 2002).

\subsection{Procedimiento y características de las lecturas digitales}

Se digitalizaron una serie de lecturas para ser utilizadas en las clases de Lengua como apoyo para el desarrollo de la competencia lectora. Para que la comparación de los distintos formatos de texto por parte del alumnado fuese precisa, se decidió digitalizar las lecturas de los libros que ya estaban siendo usados en las aulas, contando para ello con la autorización y los materiales de la editorial Edelvives, autora de los libros. De este modo, los alumnos pudieron trabajar los textos en formato digital e impreso combinadamente a lo largo del curso, recogiéndose sus valoraciones sobre estos al finalizar el mismo.

La elección de Book-Builder para digitalizar las lecturas se debió, por un lado, a que la herramienta había sido desarrollada por el CAST específicamente para atender las diversas necesidades del alumnado en el aprendizaje de la lectura según los principios del DUA y, por otro, a que los resultados obtenidos podrían ser de interés para la comunidad docente, dada la popularidad de uso de la herramienta entre las comunidades angloparlante e hispanohablante (recopila más de 7000 lecturas de acceso abierto varios idiomas diseñadas por educadores de distintos países).

Book-Builder permite diseñar lecturas con contenido en múltiples formatos: texto (con posibilidad de ser marcado), imágenes, audio y vídeos. Además, incorpora una serie de características dirigidas a apoyar distintos procesos implicados en la lectura. En la Imagen 1 se describen dichas características y en la Tabla 1 se recogen los principales procesos lectores que se ven reforzados por cada una de ellas. 
Imagen 1. Características de Book-Builder. Fuente: adaptado de Sánchez-Serrano y Arathoon-Girón (2016, p. 104)

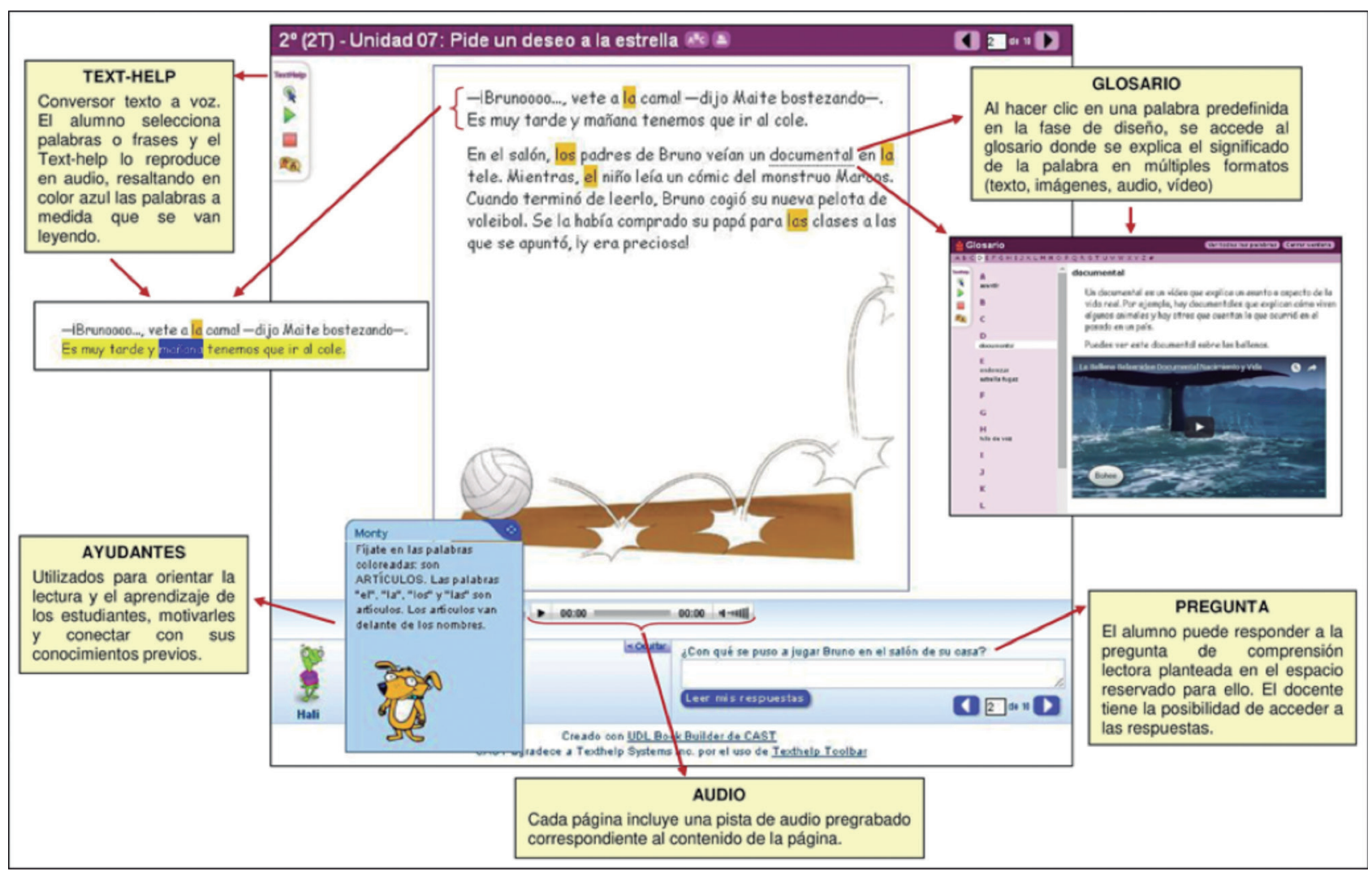

Tabla 1. Procesos lectores reforzados por Book-Builder

Características
Ayudantes
virtuales

La digitalización siguió las orientaciones del CAST y de otros trabajos (Dalton, 2014; Knight et al., 2015) sobre Book-Builder para incorporar los principios del DUA. Como resultado, fueron digitalizadas 24 lecturas, compuestas por diez páginas con texto, imágenes y una pista de audio correspondiente al texto. Además, se predefinieron palabras para el glosario, que se acompañaron de imágenes o vídeos para clarificar el significado. Asimismo, las lecturas incorporaban dos ayudantes animados a los que se asignaron distintos roles: uno "pedagógico" que explicaba contenidos relativos a reglas ortográficas y gramaticales y otro "motivador" que conectaba con los conocimientos previos y los intereses de los estudiantes.

\subsection{Muestra}

El trabajo de campo se llevó a cabo en tres centros de la Comunidad de Madrid, implicando a un total de cinco grupos de primer curso y cuatro de segundo, que incorporaron las lecturas digitalizadas en su dinámica de clase. Para la recogida de datos, se seleccionó una muestra aleatoria de 117 estudiantes, cuyas características se detallan en la Tabla 2. Tanto el procedimiento de muestreo como las encuestas fueron realizados tras obtener el consentimiento informado de las familias del alumnado. 
Tabla 2. Descripción de la muestra

\begin{tabular}{lcccc}
\hline & & $\begin{array}{c}\text { Primer curso } \\
\mathrm{N}=51\end{array}$ & $\begin{array}{c}\text { Segundo curso } \\
\mathrm{N}=66\end{array}$ & $\begin{array}{c}\text { Total } \\
\mathrm{N}=117\end{array}$ \\
\hline \multirow{2}{*}{ Sexo } & Chico & 24 & 36 & 60 \\
& Chica & 27 & 30 & 57 \\
\multirow{2}{*}{ Extranjero } & Sí & 13 & 15 & 28 \\
& No & 38 & 51 & 89 \\
2 & Sí & 6 & 7 & 13 \\
\multirow{2}{*}{ Lecesidades de } & No & 45 & 59 & 104 \\
apoyo $(* *)$ & Sí & 12 & 5 & 17 \\
\hline
\end{tabular}

${ }^{*}$ ) Si se habla otra lengua en casa además del español

$\left.{ }^{* *}\right)$ Si los tutores refieren la existencia de alguna necesidad de apoyo

\subsection{Variables e instrumento}

Se definieron ocho variables de estudio categóricas: dos referidas al grado de satisfacción con las lecturas digitales (V1) y al formato de lectura preferido (V2); y seis para medir las valoraciones de las características de dichas lecturas (V3 a V8). Los valores que podía tomar cada una de las variables vienen recogidos en la Tabla 3 .

Tabla 3. Descripción de las variables

Variable

Valores

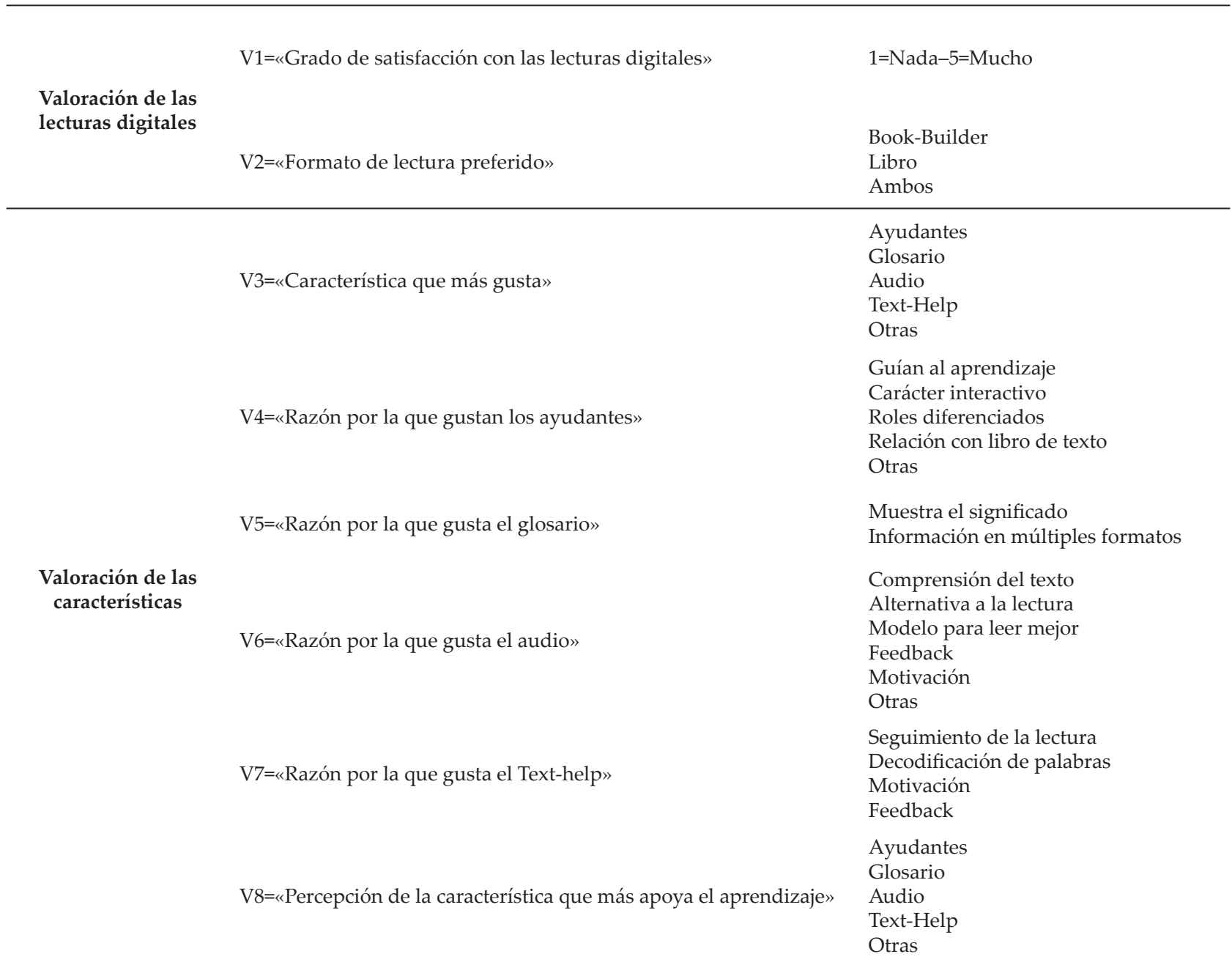


Para recabar los datos, se elaboró un cuestionario compuesto de 8 ítems (uno referido a cada variable) que combinaba preguntas de respuesta abierta y cerrada (ver Cuadro 1). Dado que los ítems 4 a 7 eran preguntas abiertas, los valores de las variables V4 a V7 fueron definidos a posteriori a partir de las respuestas dadas por los alumnos.

Cuadro 1. Preguntas del cuestionario

1. ¿Te han gustado las lecturas digitales? ¿Cuánto?

2. ¿Prefieres las lecturas de Book-Builder o el libro?

3. ¿Qué característica te gusta más?

4. ¿Te han gustado los ayudantes? ¿Por qué?

5. ¿Te ha gustado el glosario? ¿Por qué?

6. ¿Te ha gustado el audio? ¿Por qué?

7. ¿Te ha gustado el Text-help? ¿Por qué?

8. ¿Qué característica te ayuda a aprender más?

\subsection{Recogida y tratamiento de los datos}

Las encuestas fueron realizadas individualmente a los 117 alumnos y sus respuestas transcritas por los investigadores. Las variables V1, V2, V3 y V8, que se habían medido con preguntas cerradas de selección múltiple, fueron codificadas directamente a partir de la opción escogida. Para las variables V4 a V8, puesto que se trataba de preguntas abiertas en las que debían dar razones de por qué les gustaban o no las distintas características, fue necesario establecer una serie de categorías de respuesta a partir de una muestra aleatoria de entrevistas para, posteriormente, codificar las respuestas asignándolas a las categorías que habían emergido (ver Tabla 3).

Para el análisis de los datos se utilizó el software SPSS Statistics v.22. Atendiendo al carácter nominal de las variables V2 a V8, se elaboraron tablas de contingencia y se utilizó el método de significación exacta del Chi-cuadrado $\left(\chi^{2}\right)$ de Pearson $(\alpha=0,05)$ para:
- comprobar cómo la distribución de los datos recogidos para cada variable se ajustaba a la distribución teórica (prueba de bondad de ajuste);

- identificar posibles relaciones entre variables (prueba de independencia), especialmente entre las variables de estudio y las variables de la muestra: curso, sexo, condición de extranjero, $2^{a}$ lengua y necesidades de apoyo.

\section{Análisis y resultados}

Las pruebas $\chi^{2}$ de bondad de ajuste practicadas evidenciaron que la distribución observada de los datos en las diferentes variables no se ajustaba a la esperada, habiéndose obtenido en todas un valor de significación (p) menor a 0,05. Ello implica que pueden establecerse tendencias de respuesta en las valoraciones del alumnado no debidas al azar.

A continuación se analizan los resultados para cada variable en función de los objetivos del estudio, indicando, cuando existen, las diferencias en función del curso. No se incluyen referencias al sexo, condición de extranjero, 2ª lengua o necesidades de apoyo, al no haberse encontrado diferencias significativas relativas a estas variables.

\subsection{Valoración de las lecturas}

Las lecturas digitales utilizadas en el estudio fueron muy bien valoradas por los alumnos. La media de las puntuaciones para la V1 fue de $\mu=4,79$ sobre 5 , habiendo asignado esta puntuación máxima el 82,1\% y un 4 el 16,2\%. Además, dos de cada tres señalaron preferir trabajar con las lecturas en formato Book-Builder en lugar de con el libro de texto impreso (V2). Al estudiar la relación de independencia entre el "formato de lectura preferido" y el curso, se encuentran diferencias significativas $\left(\chi^{2}=6,212\right.$; $\mathrm{p}=0,043)$ : son los de primero los que eligieron el libro de texto en mayor medida (ver Gráfico 1).

Gráfico 1. Formato preferido por curso.

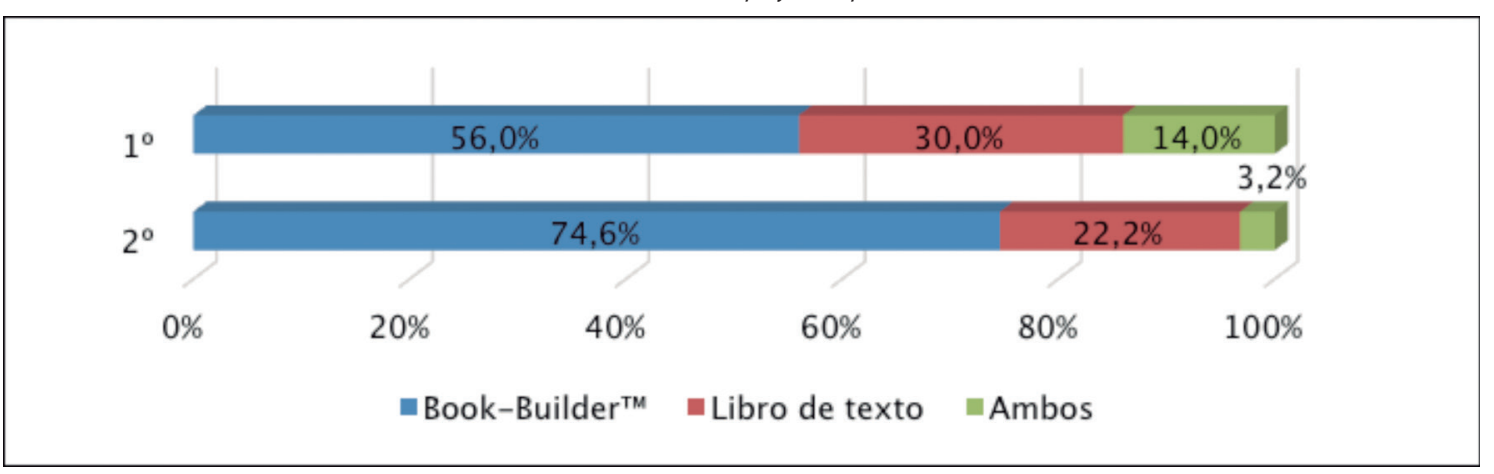

\subsection{Valoración de las características}

Los ítems 3 y 8 del cuestionario pedían al alumnado que identificara la característica de Book-Builder que más les había gustado y aquella que consideraban que era más útil para apoyar su aprendizaje. Los ayudantes fueron la característica elegida mayoritariamente para responder a ambas cuestiones. Sin embargo, al analizar la distribución de frecuencias (Gráfico 2), se observa que el glosario, a pesar de encontrarse al mismo nivel de preferencia que el resto de funcionalidades, se alza como la segunda que más apoya el aprendizaje, muy por delante del audio o el Text-help.
La prueba de independencia indicó que ambas variables no estaban relacionadas $\left(\chi^{2}=24,600 ; p=0,485\right)$, lo que significa que no señalaron la funcionalidad que consideraban que mejor apoyaba su aprendizaje en función de la que más les gustaba o viceversa. Por otro lado, la distribución de frecuencias de la V8 en función del curso es desigual en el caso del glosario, que fue la funcionalidad más elegida por los de segundo, con un $40,8 \%$ de las respuestas frente al 20,8\% de las de primero.

Por último, los ítems 4 a 7 recogían información sobre si había gustado cada una de las características y por qué. Las respuestas positivas superaron el $92 \%$ en todos los casos, excepto en el Text-help donde se registraron un $84,5 \%$. A continuación se exploran las razones de las valoraciones. 
Gráfico 2. Distribución de respuestas (V3 y V8).

V3. Característica que más gusta

V8. Característica que más ayuda a aprender

\subsubsection{Ayudantes virtuales (V4)}

Los estudiantes señalaron cuatro razones principales relacionadas con la utilidad de los ayudantes. El 49\% destacó el papel orientador y de guía del aprendizaje que desempeñaban los ayudantes en las lecturas digitalizadas al explicar conceptos del área de Lengua. Un 16,7\% apuntó el carácter interactivo de esta funcionalidad, valorando, por ejemplo, que los ayudantes virtuales les hiciesen preguntas. El 8,8\% subrayó su agrado hacia los roles diferenciados que se habían asignado a los ayudantes, identificando claramente que uno de ellos explicaba contenidos (rol pedagógico) y otro les preguntaba por sus intereses y experiencias personales (rol motivador). Por último, el hecho de que las explicaciones de los ayudantes conectaran con los contenidos que estaban trabajando en los libros de texto fue la razón del 6,9\%.

Las pruebas realizadas $\left(\chi^{2}=17,360 ; p=0,002\right)$ indican que puede establecerse una relación de dependencia entre la "razón por la que gustan los ayudantes" y el curso del alumnado. El Gráfico 3 muestra que los de primero valoraron esencialmente el papel orientador de los ayudantes $(66,7 \%)$, mientras que los de segundo también dieron importancia a su carácter interactivo $(24,1 \%)$ $\mathrm{y}$ al hecho de que el material digital no fuese un extra, sino que se integrara con los contenidos trabajados en clase $(11,1 \%)$.

Gráfico 3. Distribución de respuestas (V4) por curso.

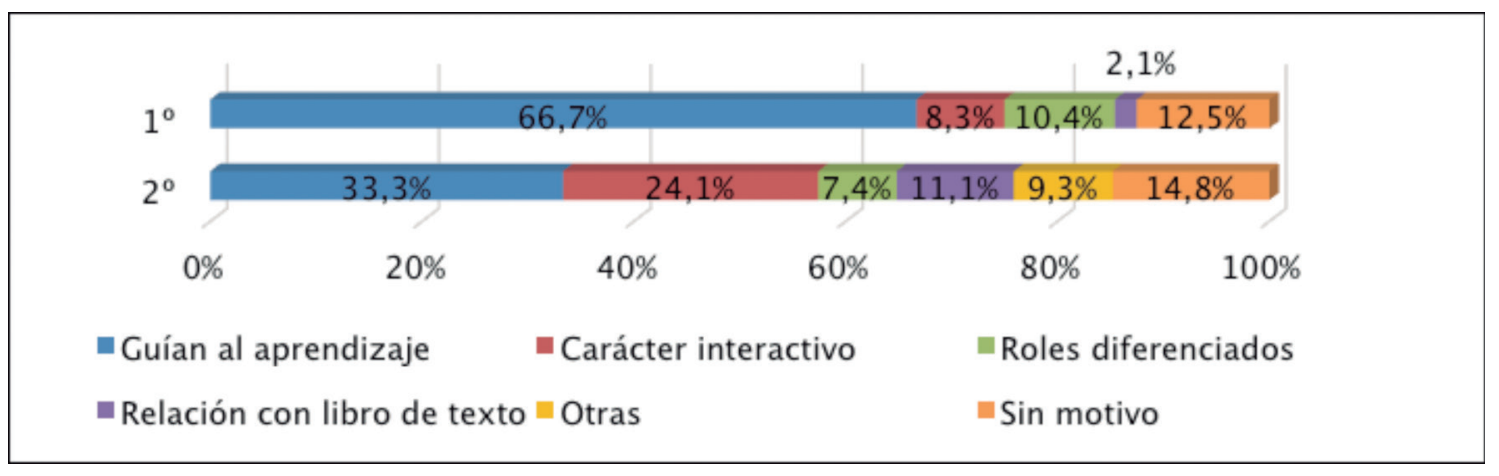

\subsubsection{Glosario (V5)}

A diferencia de lo que ocurrió con el resto de funcionalidades, el alumnado solo apuntó dos tipos de razones por las que valoraban positivamente el glosario. La mayoritaria, referida por el 66,7\%, aludía a la utilidad principal del mismo: les permitía acceder al significado de las palabras que desconocían. Puesto que esta es la respuesta que cabría esperar dada la especificidad de dicha funcionalidad, sorprende que el 21,9\% de los estudiantes haya puesto en valor, no la función semántica de esta, sino su capacidad para mostrar el significado utilizando múltiples formatos (texto, audio, imágenes o vídeos).

Cabe destacar que más de la mitad $(57,9 \%)$ de los que señalaron esta segunda razón como la principal, eligieron el glosario como la característica que más puede ayudarles a aprender (V8) (ver Gráfico 4). De hecho, existe una relación de dependencia

Gráfico 4. Distribución de respuestas para V8 según la razón señalada para V2.

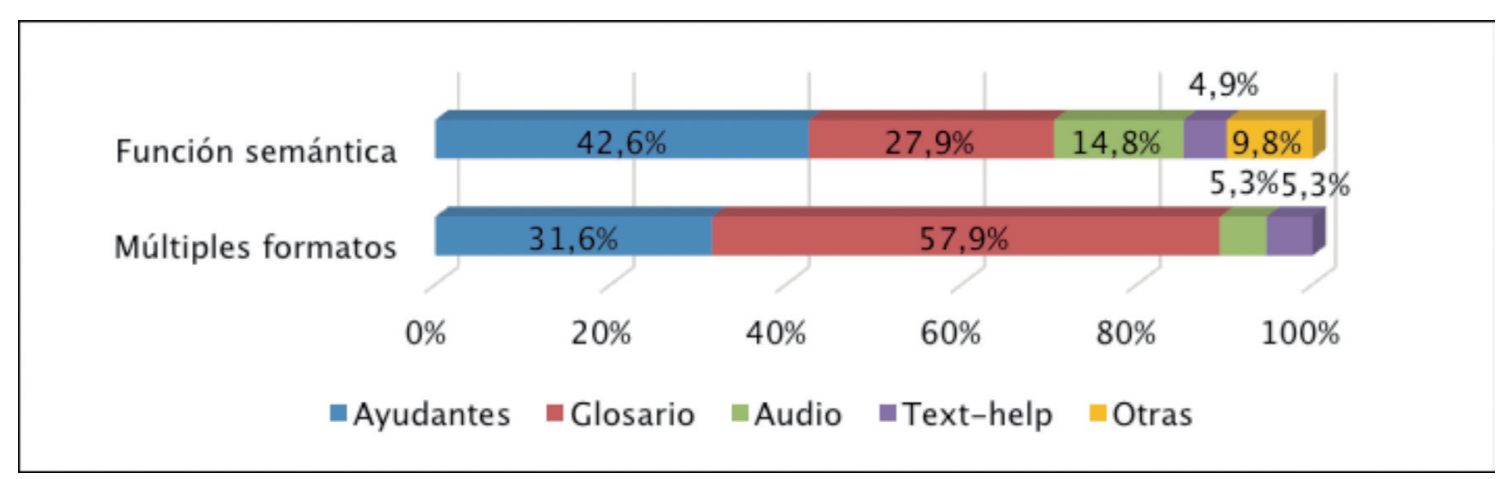


entre ambas variables: "razón de por qué ha gustado el glosario" (V5) y "característica que más apoya el aprendizaje" (V8) $\left(\chi^{2}=20,742 ; p=0,010\right)$. Es decir, una buena parte de aquellos que reconocen un potencial en el glosario para mostrar el significado de múltiples formas, se decantan por señalarlo como el mayor apoyo al aprendizaje de Book-Builder.

\subsubsection{Audio (V6)}

Con respecto a la posibilidad de escuchar el texto a través de grabaciones de audio en cada página, más allá del elemento motivador que supone escuchar la voz de los personajes de las lecturas (referido únicamente por el 6,4\%), el alumnado mostró su satisfacción debido principalmente a que les ayudaban a comprender mejor la lectura $(23,6 \%)$ y a que permitían acceder a los contenidos sin necesidad de leer cuando, por ejemplo, estaban fatigados $(22,7 \%)$. Además, también señalaron que servía de modelo para una lectura de mayor calidad (entonación o ritmo) $(11,8 \%)$ y era útil para comprobar si habían leído correctamente $(10 \%)$. Las dos primeras razones apuntarían la utilidad del audio para acceder al contenido (comprensión) y las otras dos su importancia para apoyar el proceso de lectura actuando como modelo y aportando feedback. Es en estas últimas en las que se aprecian diferencias entre cursos: los de segundo señalan en mayor medida la utilidad como modelo y los de primero la posibilidad de recibir feedback (ver Gráfico 5).

Gráfico 5. Distribución de respuestas (V6) por curso.

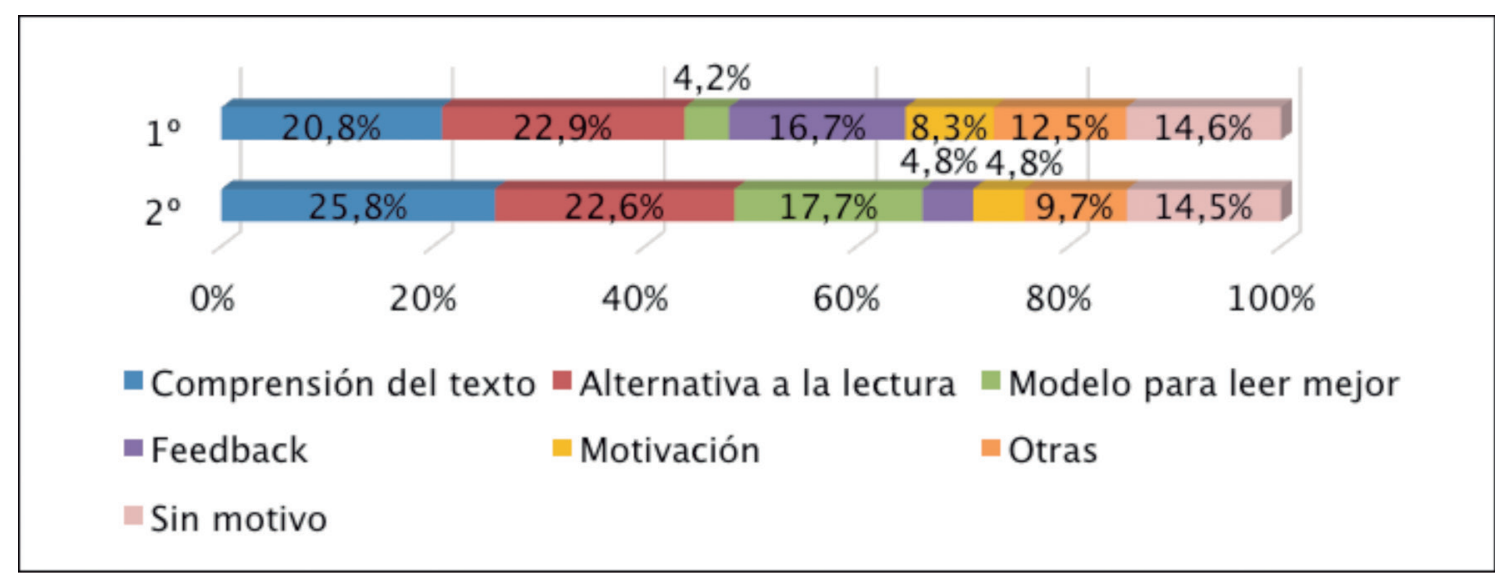

\subsubsection{Text-Help (V7)}

El conversor texto-voz fue valorado positivamente porque, según expresaron, les ayudaba a no perderse en la lectura resaltando el texto en color (39\%) y por su utilidad para decodificar aquellas palabras que les costaba leer $(22,1 \%)$. En menor medida apuntaron la motivación que les despertaba poder escuchar la palabra seleccionada $(11,7 \%)$ y la función de feedback para comprobar la precisión de la lectura realizada $(6,5 \%)$. No se encontraron diferencias significativas en función del curso.

\section{Discusión y conclusiones}

Los datos expuestos apoyan la idea de que el uso de los medios digitales resulta altamente motivador para el alumnado, tal como se ha referido en el marco teórico (Moody, 2010). Así, más de un $98 \%$ del alumnado valoró positivamente las lecturas diseñadas en Book-Builder y la mayoría se decantó por el formato digital frente al libro de texto, coincidiendo con el estudio de De Oliveira et al. (2014) respecto a la preferencia de utilizar los libros digitales.

Entendiendo que los materiales curriculares, incluidos los digitales, se diseñan con el propósito de apoyar y guiar el aprendizaje del alumnado, parece pertinente conocer la opinión de estos como una forma más de validación de los mismos. Si bien podrían surgir dudas sobre si niños de 6 y 7 años están capacitados para ello, los resultados del estudio demuestran que no solo sí que lo están, sino que a esta edad temprana ya son capaces de discriminar aquello que les gusta (V3) de aquello que apoya su aprendizaje (V8), no habiéndose encontrado dependencia entre ambas variables. En esta misma línea, sorprende que las respuestas espontáneas del alumnado al valorar las distintas características, lejos de girar en torno a preferencias estéticas y otros aspectos ligados a la motivación, se centran en resaltar su utilidad para el aprendizaje de la lectura. Todo ello invita a reflexionar sobre la pertinencia de validar los materiales didácticos con los usuarios últimos a los que están dirigidos, aunque sean de corta edad, como sugiere Druin (2002). Asimismo, se hace evidente que el alumnado es consciente o percibe las propias necesidades en relación con el aprendizaje, lo cual indica la conveniencia de potenciar la utilización de métodos y materiales didácticos que favorezcan el aprendizaje autónomo, la personalización y la implicación, en la línea de lo que propone el modelo DUA y que permiten los formatos multimedia (Meyer et al., 2014).

Por otro lado, debido a la celeridad con que se desarrollan y lanzan nuevas herramientas digitales educativas al mercado, los docentes pueden sentirse sobrepasados ante la cantidad de recursos disponibles, siendo complicado discernir cuáles son más apropiados para apoyar qué tipo de aprendizaje y a qué tipo de alumnos. Estudios como este, que se centran en analizar los "andamiajes" que incorporan dichas herramientas, podrían ser de gran utilidad en la selección de recursos para la enseñanza, pues permiten al docente escoger en base a criterios de usabilidad y utilidad para el aprendizaje y contribuyen, en parte, a superar el hándicap que supone su falta de formación en materia de TIC y software para atender la diversidad, apuntada por Fernández-Batanero et al. (2017) o González-Gil et al. (2017). Así, basándose en las valoraciones de las características técnicas de Book-Builder, el docente podría elegir aquellos recursos que incorporen las funcionalidades más convenientes para atender diferentes necesidades o ritmos, proporcionando múltiples formas de acceso al contenido y su decodificación para apoyar y reforzar los procesos implicados en la lectura; por ejemplo, funcionalida- 
des tipo glosario o ayudantes virtuales para apoyar los procesos semánticos, o conversores texto-voz y grabaciones de audio para los procesos léxicos, siendo más convenientes los primeros para la decodificación (ruta fonológica) y los segundos para modelar aspectos prosódicos del lenguaje como la entonación o el ritmo (ruta visual).

Cabe también señalar otras consideraciones sobre el potencial de Book-Builder para atender la diversidad. En primer lugar, la dispersión de respuestas en todas las variables muestra cómo estudiantes distintos apuntan razones distintas de cómo una misma característica apoya su aprendizaje o cuál es la que más ayuda a aprender. Ello es un indicador de su multifuncionalidad, lo que permite al docente ajustar el contenido a ciertas necesidades y preferencias individuales y a los estudiantes poder utilizarlos con autonomía, seleccionando aquellos componentes que le sirven de apoyo en el proceso de lectura.

En segundo lugar, cobran importancia las diferencias en la distribución de respuestas en función del curso. Por ejemplo, la utilidad del audio para saber si se ha leído bien es señalada mayoritariamente por el alumnado de primero, mientras que su utilidad para leer mejor es una razón propia del de segundo, diferencia que podría explicarse en base a la etapa de desarrollo de la lectura en que se encuentran, alfabética (con predominio de la ruta fonológica) y ortográfica (relevancia de la ruta visual) respectivamente (Frith, 1985), lo que en la práctica permite la utilización de las características de Book-Builder con fines diferentes para apoyar de forma flexible los procesos lectores en función de los niveles de competencia de los estudiantes. Asimismo, el hecho de que el porcentaje de estudiantes de segundo que consideran el glosario como la característica que más ayuda a aprender doble al de los de primero, apunta a la mayor relevancia que toma la comprensión del texto a través de los procesos semánticos cuando no se tiene que focalizar la atención y el esfuerzo en la decodificación de palabras.

Los resultados obtenidos han permitido conocer la percepción positiva que los estudiantes tienen de las lecturas digitales diseñadas con Book-Builder, destacando su preferencia por este formato y especialmente por los ayudantes virtuales y el glosario como las características que más contribuyen a su aprendizaje, en la línea de la investigación de Knight et al. (2015) en el contexto estadounidense; y cómo, junto con el resto de características, pueden permitir proporcionar respuestas flexibles a diferentes necesidades de los estudiantes en el proceso de lectura. Se ha puesto de manifiesto también la adecuación de recoger información de los usuarios finales de los materiales didácticos utilizados en los procesos de enseñanza por la relevancia de la información que pueden facilitar, al identificar con claridad los diferentes componentes de los textos digitales y asignarles diferentes funciones para los procesos lectores. Las limitaciones derivadas de las características del estudio no permiten la generalización de estos resultados, pero los datos apuntan a poder considerar Book-Builder como una herramienta idónea para apoyar el desarrollo de la competencia lectora, dada su facilidad de uso, sus posibilidades didácticas, el potencial para atender la diversidad y la buena acogida entre el alumnado. Conectado con esta limitación, en futuros estudios sería valioso incorporar también la percepción de los propios docentes, además de señalar la necesidad de formación de estos sobre el diseño y uso de este tipo de recursos digitales en los procesos de enseñanza para atender la diversidad del alumnado.

Por último, los resultados abren nuevas líneas de investigación que permitan conocer en estudios más amplios, no solo el potencial percibido en las características de Book-Builder para apoyar la lectura, sino si ello se traduce en una mejora del apren- dizaje de todos los estudiantes, tal como plantea la filosofía del DUA.

\section{Apoyos}

Trabajo vinculado al proyecto de investigación DUALETIC. Aplicación del Diseño Universal para el Aprendizaje y utilización de materiales digitales accesibles: implicaciones para la enseñanza de la lectoescritura y formación del profesorado (EDU201124926), financiado por el Ministerio de Economía y Competitividad. Plan Nacional de I+D+i 2008-2011. Subprograma de Proyectos de Investigación Fundamental No Orientada 2011-2014.

José Manuel Sánchez-Serrano es beneficiario de un contrato predoctoral otorgado por la Universidad Complutense de Madrid (UCM) y financiado por el Banco Santander.

\section{Referencias bibliográficas}

Alba-Pastor, C. (Coord.) (2016). Diseño Universal para el Aprendizaje: Educación para todos y prácticas de Enseñanza Inclusivas. Madrid: Morata

Alba-Pastor, C., Zubillaga, A., y Sánchez-Serrano, J.M. (2015). Tecnologías y Diseño Universal para el Aprendizaje (DUA): Experiencias en el contexto universitario e implicaciones en la formación del profesorado. RELATEC: Revista Latinoamericana de Tecnología Educativa, 14(1), 89-100. http://dx.doi.org/10.17398/1695-288X.14.1.89

Azorín, C.M., y Arnáiz, P. (2013). Una experiencia en innovación en educación primaria: medidas de atención a la diversidad y diseño universal del aprendizaje. Tendencias Pedagógicas, 22, 9-30. (https://goo.gl/vh0obc).

Biancarosa, G., y Griffiths, G. (2012). Technology Tools to Support Reading in the Digital Age. Future of Children, 22(2), 139-160. https://doi.org/10.1353/foc.2012.0014

Claro, M. (2010). Impacto de las TIC en los aprendizajes de los estudiantes. Estado del arte. Santiago de Chile: Naciones Unidas. (http://goo.gl/M5k3Ff).

Coll, C. (2009). Aprender y enseñar con las TIC: expectativas, realidad y potencialidades. En R. Carneiro, J.C. Toscano y T. Díaz (Coords.), Los desafíos de las TIC para el cambio educativo (pp. 113-126). Madrid: Santillana.

Cuadrado, I., y Fernández, I. (2009). Funcionalidad y niveles de integración de las TIC para facilitar el aprendizaje escolar de carácter constructivista. IE Comunicaciones: Revista Iberoamericana de Informática Educativa, 9, 22-34. (http://goo.gl/o1hwBF).

Cuetos, F. (1990). Psicología de la lectura. Madrid: Escuela Española.

Dalton, B. (2014). DIY E-Books. Designing Enhanced Texts. The Reading Teacher, 67(7), 543-546. http://dx.doi.org/10.1002/ trtr.1246

De Oliveira, J., Camacho, M., y Gisbert, M. (2014). Explorando la percepción de estudiantes y profesor sobre el libro de texto electrónico en Educación Primaria. Comunicar, 50, 87-95. http://dx.doi.org/10.3916/C42-2014-08

Druin, A. (2002). The Role of Children in the Design of New Technology. Behaviour \& Information Technology, 21(1), 1-25. http://dx.doi.org/10.1080/01449290110108659

Edyburn, D.L. (2010). Would you Recognize Universal Design for Learning if You Saw It? Ten Propositions for New Directions for the Second Decade of UDL. Learning Disability Quarterly, 33(1), 33-41. http://dx.doi.org/10.1177/073194871003300103

Ely, D.P. (1987). Educational Technology Research: a Status Report on Classroom Applications. Education Media International, 24(2), 74-78. http://dx.doi.org/10.1080/0952398870240204 
Estévez, M.E. (2012). Análisis y beneficios de la incorporación de las TIC en el área de lengua castellana y literatura: un caso práctico. Píxel-Bit. Revista de Medios y Educación, 40, 21-34. (http://goo.gl/4g0x8I).

Fernández-Batanero, J.M., Román, P. y El-Homrani, M. (2017). TIC y discapacidad. Conocimiento del profesorado de educación primaria en Andalucía. Aula Abierta, 46, 65-72. https:// doi.org/10.17811/rifie.46.2017.65-72

Frith, U. (1985). Beneath the Surface of Developmental Dyslexia. En K.E. Patterson, J.C. Marshall y M. Coltheart (Eds.), Surface Dyslexia: Neuropsychological and Cognitive Studies of Phonological Reading (pp. 301-330). Londres: Erlbaum.

García, M., y Cotrina, M. (2012). La contribución de la universidad al desarrollo de prácticas inclusivas: dilemas y propuestas para avanzar compartiendo. Revista de Educación Inclusiva, 5(1), 123-138. (http://goo.gl/KvCC33).

García-Valcárcel, A., y Tejedor, F.J. (2017). Percepción de los estudiantes sobre el valor de las TIC en sus estrategias de aprendizaje y su relación con el rendimiento. Educación XX1, 20(2), 137-159. https://doi.org/10.5944/educxx1.19035

González, M. (2014). The Effect of Embedded Text-to-Speech and Vocabulary Ebook Scaffolds on the Comprehension of Students with Reading Disabilities. International Journal of Special Education, 29(3), 111-125. (http://goo.gl/NXZEjR).

González, M.J., y Delgado, M. (2009). Rendimiento académico y enseñanza-aprendizaje de la lectoescritura en Educación Infantil y Primaria: un estudio longitudinal. Infancia y Aprendizaje: Journal for the Study of Education and Development, 32(3), 265-276. http://dx.doi.org/10.1174/021037009788964114

González-Gil, F., Martín-Pastor, E. y Orgaz-Baz, B. (2017). ¿Están los futuros profesores formados en inclusion?: Validación de un cuestionario de evaluación. Aula Abierta, 46, 33-40. https:// doi.org/10.17811/rifie.46.2017.33-40

Hattie, J. (2009). Visible Learning: A Synthesis of Over 800 MetaAnalyses Relating to Achievement. Londres: Routledge.

Hidalgo, E., y Manzano, M. (2014). El proceso de comprensión en una lengua extranjera: Una propuesta para evaluar estrategias de lectura. Educación XX1, 17(1), 309-326. http://dx.doi. org/10.5944/educxx1.17.1.10716

Jiménez, E., y O'Shanahan, I. (2008). Enseñanza de la lectura: de la teoría y la investigación a la práctica educativa. Revista Iberoamericana de Educación, 45/5, 1-22. (http://goo.gl/SM8wlH).

Knight, V.F., Wood, C.L., Spooner, F., Browder, D.M., y O'Brien, C.P. (2015). An Exploratory Study Using Science eTexts with Students with Autism Spectrum Disorder. Focus on Autism and Other Developmental Disabilities, 30(2), 86-99. https://doi. org/10.1177/1088357614559214

Kruger, J., Doherty, S. y Soto-Sanfiel, M.T. (2017). Subtítulos en lengua original: sus efectos en el espectador nativo y extranjero. Comunicar, 50, 23-32. https://doi.org/10.3916/C50-2017-02

Méndez, I. (2015). Prácticas docentes y rendimiento estudiantil. Evidencia a partir de TALIS 2013 y PISA 2012. Gobierno de La Rioja, Fundación Santillana, Instituto Nacional de Evaluación Educativa (INEE). (http://goo.gl/bOHi81).

Méndez, M., y Fidalgo, R. (2009). Revisión empírica de la instrucción estratégica y auto-regulada en la comprensión lectora: el estado de la cuestión en España. International Journal of De- velopmental and Educational Psychology, 1(1), 167-174. (http:// goo.gl/rwOsG5).

Meyer, A., Rose, D.H., y Gordon, A. (2014) Universal Design for Learning: Theory and Practice. Wakefield, MA: CAST Professional Publishing.

Moody, A.K. (2010). Using Electronic Books in the Classroom to Enhance Emergent Literacy Skills in Young Children. Journal of Literacy y Technology, 11(4), 22-53. (http://goo.gl/MszIjM).

Morra, T., y Reynolds, J. (2010). Universal Design for Learning: Application for Technology-Enhanced Learning. Inquiry, 15(1), 43-51. (http://goo.gl/OBpgQX).

Narkon, D.E., y Wells, J.C. (2013). Improving Reading Comprehension for Elementary Students with Learning Disabilities: UDL Enhanced Story Mapping. Preventing School Failure, 57(4), 231-239. http://dx.doi.org/10.1080/1045988X.2012.726286

Novak, K. (2014). UDL Now!: A Teacher's Monday-Morning Guide to Implementing Common Core Standards using Universal Design for Learning. Wakefield, MA: CAST Professional Publishing.

Philip. G.C., y Moon, S.Y. (2013). An Investigation of Student Expectation, Perceived Performance and Satisfaction of E-Textbooks. Journal of Information Technology Education: Innovations in Practice, 12, 287-298. (https://goo.gl/y4Ij1X).

Reynolds, R. (2011). Trends Influencing the Growth of Digital Textbooks in US Higher Education. Publishing Research Quarterly, 27(2), 178-187. http://dx.doi.org/10.1007/s12109-0119216-5

Rose, D.H., y Meyer, A. (2002). Teaching Every Student in the Digital Age: Universal Design for Learning. Alexandria: Association for Supervision and Curriculum Development.

Rose, D.H., Gravel, J.W., y Domings, Y. (2012). Universal Design for Learning "Unplugged": Applications in Low-Tech Settings. En T. Hall, A. Meyer y D.H. Rose (Eds.), Universal Design for Learning in the Classroom: Practical applications (pp. 120-134). New York: Guilford Press.

Sáez, J.M. (2012). Valoración del impacto que tienen las TIC en educación primaria en los procesos de aprendizaje y en los resultados a través de una triangulación de datos. RELATEC: Revista Latinoamericana de Tecnología Educativa, 11(2), 11-24. (http://goo.gl/XrdLQ6).

Salomon, G., y Clark, R. (1977). Reexamining the Methodology of Research on Media Technology in Education. Review of Educational Research, 47(1), 99-120. http://dx.doi. org/10.3102/00346543047001099

Sánchez-Serrano, J.M., y Arathoon-Girón, A.I. (2016). Recursos digitales y Diseño Universal para el Aprendizaje. En Alba-Pastor, C. (Coord.) Diseño Universal para el Aprendizaje: Educación para todos y prácticas de Enseñanza Inclusivas (pp. 89122). Madrid: Morata.

Soria, A. (2015). Estudio de los efectos del formato hipertextual en la comprensión lectora y la memoria textual en niños de educación primaria. Educación XX1, 18(1), 369-390. http://10.5944/educXX1.18.1.12394

Zubillaga, A., y Alba-Pastor, C. (2013). La discapacidad en la percepción de la tecnología entre estudiantes universitarios. Comunicar, 40, 165-172. http://dx.doi.org/10.3916/C40-201303-07 